\title{
General practice: a leading provider of medical student education in the 21 st century?
}

\author{
Jill E Thistlethwaite, Michael R Kidd and Judith N Hudson
}

$\mathrm{F}$ or millennia, the training of doctors took place in the community under the apprenticeship model. Over the past 100 years, the principal location for medical learning has become the hospital - usually a tertiary care facility attached to a university medical school. However, in developed countries, the changing nature of health care provision and disease profiles has led to a reassessment of the optimum clinical settings in which students should learn. While student experience currently occurs predominantly in hospitals, patients are mainly diagnosed and treated in the community, with only short forays into inpatient care. ${ }^{1}$ Moreover, patients with chronic disease are now managed primarily within general practice, where the majority of health promotion and disease prevention is also carried out. ${ }^{2}$ It is time to consider whether the balance should shift towards a higher proportion of medical education delivery in community settings - particularly, but not exclusively, in general practice.

In 1988, the World Federation for Medical Education advocated a substantial transfer of education from teaching hospitals to community settings. ${ }^{3}$ In 1993, the General Medical Council in the United Kingdom recommended that students should have more community-based education to enhance their exposure to a more holistic delivery of health care. ${ }^{4}$ Resulting changes in medical education delivery were further influenced by a subsequent and ongoing reduction in the number of hospital beds, ${ }^{5}$ leading to an enhanced role for primary care and general practice. This role has been evaluated and endorsed. ${ }^{6}$ Over the past decade, an international body of evidence has added credence to the vision that general practice will become a major setting for medical student learning in Australia this century.

\section{General practice in the medical curriculum - past and current developments}

University departments of general practice and community medicine are a relatively new addition to academic medical education in Australia, having been first established in the early 1970s following the Karmel report, ${ }^{7}$ which advocated that medical students should be exposed to general practice during their training. Before this time, general practice had been seen by some in the medical community as lacking prestige as a career and academic rigour as a discipline. ${ }^{8}$ This has now changed. ${ }^{9}$

University medical school accreditation, introduced by the Australian Medical Council in the 1980s, included the requirement that there should be an even greater emphasis on general practice. Subsequently there was an additional mandate that part of this experience should be in rural communities. Rural attachments were provided mainly through rural general practices. Even with the more recent establishment of rural clinical schools attached to large rural hospitals, the medical student teaching workload often rests with general practitioners whose practice includes work in both smaller rural hospitals and communitybased clinics. Rural teaching has been supported through federal government grants such as the Rural Undergraduate Support and Coordination Program. ${ }^{10}$
ABSTRACT

- General practice is well placed to become a major setting for medical student education over the next decade.

- New models of clinical education are required, to take account of changes in the patient population, disease profile and management strategies.

- While there has been an increase in general practice-based and other community-based education, there is the potential for further expansion. Evidence for the positive role of general practitioners and general practice in medical education is growing, including the benefits of prevocational training in general practice.

- If GPs are to assume a major role in community-based education of medical students, there will need to be changes in funding structures and supporting resources, particularly at this time of increasing medical student numbers and workforce shortage and maldistribution.

MJA 2007; 187: 124-128

For editorial comment, see page 66. See also pages 129 and 133

\section{Justification for increased learning in general practice}

It is difficult to define the learning outcomes for general practice attachments given that almost all medical conditions may be encountered in the community. While there are specific outcomes that can only be learnt in general practice (eg, the context of family medicine, continuity of care, early presentation of disease, and undifferentiated illness), there are only a few outcomes that cannot be met - for example, intensive care of the acutely ill patient. GPs have also become involved in facilitating student learning in generic areas such as communication and consultation skills and dealing with uncertainty. Major benefits of the general practice learning environment include the opportunity for learners to participate in diagnosis and management planning involving undifferentiated patients, as well as learning about the full spectrum of community-based care, including chronic disease management, preventive care, mental health and population health.

\section{Community-based education}

The World Health Organization defined community-based education in 1987 as learning activities that take place within the community in which not only students but also teachers and patients are actively engaged throughout the educational experience. Community-based education can be implemented wherever people live, in rural, suburban or urban areas. ${ }^{11}$

Community learning for medical students is now expected to encompass much more than the traditional general practice attachment of earlier curricula. Traditionally these attachments were for periods of 2-8 weeks in the latter years of the medical course and were usually combined with some medical school-based didactic teaching as well. Newer curricula involve students in early patient contact in the community and clinical skills teaching in general 


\section{GENERAL PRACTICE AND MEDICAL EDUCATION — FOR DEBATE}

practice, together with extensive attachments in later years in urban, regional and rural general practices. In their role as coordinators of patient care, GPs are well placed to coordinate learning plans for medical students and align student learning with patient care.

\section{International evidence that general practice and community-based attachments do work}

Newer models of educational delivery in general practice have been evaluated and compare favourably with hospital-based education. Students at University College London learn internal medicine both in a tertiary teaching hospital and in general practice, with 4 weeks in each setting. This has provided evidence that clinical skills and methods can be learnt as effectively in primary as in secondary care settings. ${ }^{12}$ Students endorse GP teaching of clinical skills ${ }^{13}$ and are more likely to develop a patient-centred approach to patient care ${ }^{14,15}$ and a shared decision-making model when learning communication skills in general practice settings. ${ }^{16}$

Longer longitudinal attachments have also been introduced. At Cambridge University, Nigel Oswald pioneered a general practice attachment that ran throughout the clinical years, with students following patients between primary and secondary care. This initiative developed into the Cambridge Graduate Course in 2001. Students spend 2 days a week in a general practice and 3 days in the local district hospital. An extensive qualitative and quantitative evaluation concluded that the course was regarded as a good model for training doctors by all stakeholders - GPs, hospital doctors, patients, practice staff and students. ${ }^{17}$ The difficulties in this program that the Cambridge team discuss have implications for general practice teaching and will be considered below under "Implications for general practice".

In the United States, the outcomes of several medical school programs have supported primary care as a valuable setting for medical education. ${ }^{18,19}$ The Rural Physician Associate Program in Minnesota has been training students in rural communities for more that 30 years. Students recognise the value of a learning environment in which they experience continuity of care, and $62 \%$ of students trained by the program currently practise as primary care physicians. ${ }^{18}$

\section{Australian evidence}

In Australia, the Flinders Parallel Rural Community Curriculum, based on the Cambridge Graduate Course, involves senior students undertaking a whole clinical year in rural general practice, during which they learn internal medicine, paediatrics, women's health and mental health, as well as the context of general practice itself. ${ }^{20}$ Students following the Parallel Rural Community Curriculum program perform better in written and clinical examinations than their hospital-based peers. ${ }^{21}$ In comparison with students in tertiary hospitals, the community-based students feel more valued by the supervising doctors and their patients and have greater opportunities to "meet the aspirations of both the community and government policy" and to "learn how their professional expectations can mesh with their own personal values". 22 Similar examination performance has been found for extended rural placements at the University of Queensland. ${ }^{23}$

General practice is also a fertile educational experience for prevocational doctors. General practice rotations for junior doctors have been part of Australian general practice training for decades, but have had a recent boost through the establishment of the Postgraduate General Practice Placement Program (PGPPP) in 2003. Interns have found that such posts provide them with learning opportunities not found in hospital rotations. ${ }^{24}$ An evaluation of similar posts in the UK showed that they offered a wide range of learning, including much that was communityspecific, such as social factors in illness, referral and information technology skills. Moreover, general practice fostered more indepth reflection on learning. The conclusion was that the UK scheme demonstrated a positive net educational impact in content and process. ${ }^{25}$

\section{Proposed models and learning opportunities}

Learning outcomes for general practice and community-based education are shown in Box 1. The challenge is to distinguish which learning outcomes are best pursued in which setting, based on educational value and cost-effectiveness. Students should learn in small groups in general practice in their early years, moving to longer and more intensive attachments in their senior years, with time spent in urban and rural settings. After graduation, we would advocate that all junior doctors have time within the PGPPP in the first and second postgraduate years.

\section{GPs as teachers}

To increase the amount of time that students and junior doctors spend in general practice at a time when medical student numbers are increasing ${ }^{26}$ will require a substantial increase in the number of GP teachers. There is already a network of trained GP educators. GP supervisors who provide vocational training for general practice registrars are required to attend professional development courses in medical education as part of their contracts. Many of these GPs also provide training through the PGPPP and have medical students

1 Examples of learning and potential learning in general
practice

\begin{tabular}{|c|c|c|}
\hline Generic outcomes & $\begin{array}{l}\text { General practice } \\
\text { outcomes }\end{array}$ & $\begin{array}{l}\text { Discipline-specific } \\
\text { outcomes }\end{array}$ \\
\hline Communication skills & Evolution of disease & Internal medicine \\
\hline Teamwork & Community deprivation & Child health \\
\hline Indigenous health & Undifferentiated disease & Maternal health \\
\hline Health inequalities & Practice administration & Women's health \\
\hline $\begin{array}{l}\text { Australian health care } \\
\text { system }\end{array}$ & $\begin{array}{l}\text { Nature of chronic } \\
\text { disease }\end{array}$ & Men's health \\
\hline Interprofessional care & Continuity of care & Mental health \\
\hline Multiple medication & Disease prevention & Sexual health \\
\hline $\begin{array}{l}\text { Complementary } \\
\text { medicine }\end{array}$ & Early presentation & Dermatology \\
\hline Medical informatics & $\begin{array}{l}\text { Context of family } \\
\text { medicine }\end{array}$ & $\begin{array}{l}\text { Ear, nose and } \\
\text { throat }\end{array}$ \\
\hline $\begin{array}{l}\text { Ethics and } \\
\text { professionalism }\end{array}$ & Palliative care & Musculoskeletal \\
\hline Cultural competence & Health promotion & Care of the elderly \\
\hline $\begin{array}{l}\text { Evidence-based } \\
\text { practice }\end{array}$ & & \\
\hline
\end{tabular}




\section{GENERAL PRACTICE AND MEDICAL EDUCATION - FOR DEBATE}

2 Requirements for a national plan to take forward the vision of general practice as a leading site for medical education

- Examine the projected number of medical students and estimate the demands on general practice time and resources, including the number of teaching practices required over the next 10 years. Ensure that there are enough prevocational and vocational training places for these students when they graduate.

- Survey existing practices and general practitioners to explore their ideas and concerns about an increased teaching load, particularly in relation to GPs who work part-time.

- Provide infrastructure, including information technology (IT) (eg, high-speed web links and videoconferencing) and human resources (eg, part-time staff to develop and administer a sustainable educational program) to meet GP and practice needs to provide quality education in public and private practices.

- Provide infrastructure and support to meet student needs, including accommodation (consulting, study and residential) and IT. This may include building additional rooms at clinics and will require exploration of funding mechanisms such as grants and interest-free loans.

- Explore the ideas and concerns of patients and provide opportunities for patients to be involved proactively in teaching.

- Explore opportunities for other community-based groups, health services and health professionals to provide interprofessional educational experiences for all health care students.

- Discuss the role of universities in providing educational and pastoral support to GP educators and their staff, with regular visits to practices.

- Provide a funding model remuneration package for general practice that acknowledges the role of GPs and practices and encourages practices to enhance this role, over and above Practice Incentive Payments for face-to-face teaching.

- Clarify indemnity issues relating to educational input and student involvement in patient care.

- Encourage research and development around community-based education and change in educational delivery based on best practice.

within their practices. The regionalised training model established initially by the Royal Australian College of General Practitioners and now rolled out through the 22 regional training providers across Australia has increased the number of teaching practices and GP supervisors. Australian Government requirements for registrars to gain experience in rural and outer metropolitan general practice have also provided opportunities for new teaching practices. This has created a cohort of GP educators who may not only become more involved in medical student teaching, but who can also act as mentors for new tutors. Moreover, academic units of general practice have been recruiting and training more GPs to teach within universities as well as in the community. Studies have shown that GPs enjoy teaching, that it increases their morale and that it encourages them to keep up-to-date. ${ }^{27,28}$ These positive benefits should help retain existing teachers and recruit new ones. However, more GPs will be needed, at a time when the workforce is ageing, and the emphasis has to be on quality as well as quantity.

The new junior doctor and GP vocational training curricula recognise the need for doctors-in-training to develop expertise in educational delivery. General practice registrars, like hospital-based registrars, will have a major role in teaching medical students, which will benefit the registrars, the students and the supervisors.

\section{The case for community-based education in relation to general practice workforce issues}

General practice as a career choice had declined in popularity during the past 10 years. ${ }^{26}$ The crisis in recruitment and retention of rural doctors is well known. ${ }^{29}$ There are a number of factors that appear to promote general practice as a career, including higherquality and longer general practice attachments with positive GP role models. ${ }^{30}$ The main factor affecting a doctor's choice to practise in a rural location is whether he or she has a rural background, ${ }^{31}$ although positive experiences during training and having longer attachments in rural areas have some impact. ${ }^{32}$ Early findings from the UK, where doctors in the first 2 years after graduation work for 4 months in general practice, are that the number of doctors intending to train as GPs has started to rise. ${ }^{33,34}$

\section{Implications for general practice}

With increasing student numbers and a less than optimal number of GPs, it is difficult to see how this model will work without a national plan, as proposed in Box 2. Australian medical student numbers are projected to increase by $81 \%$ - from 1348 in 2005 to 2442 in $2012^{26}$ — with a subsequent rise in the number of junior doctors. These numbers do not include fee-paying international students and international students on elective terms seeking experience in Australian general practice.

If every student and junior doctor, as well as general practice registrar, is to spend a quality amount of time in general practice, this has major implications not only for medical schools and general practices, but also for practice staff, patients and government funding (Box 3). ${ }^{35}$ While the evaluation report of the Cambridge Graduate Course found that having students for long times in general practice did not adversely affect patient satisfaction and did not markedly disrupt practices as a whole, GPs did find that their expanded teaching role was tiring and added to the complexity and pressure of their work. ${ }^{17}$

Many GPs wish to teach but do not have space in their practices for students to be actively involved in seeing patients. They are concerned about their lack of training in medical education. Many feel they do not have the time to devote to quality student teaching because of the demands of patient care. If GPs take students under these circumstances, it may be that students will simply observe clinical interactions rather than interact with patients themselves. Many practices will need additional rooms if they are to provide this level of experience, but who will be expected to pay for the building works? - the practices or the local community, the universities or the government? In rural areas, safe and adequate accommodation is needed for students. This is in short supply in many areas, and the amount of available local hospital accommodation is inadequate for projected needs. The model of students living with rural doctor families is not sustainable if student numbers increase and attachments become longer. The reliance on health professional altruism to provide quality education to increasing numbers of students will not sustain this enhanced model.

In relation to general practice medical education funding, the Australian Association of Academic General Practitioners recommends: 


\section{GENERAL PRACTICE AND MEDICAL EDUCATION - FOR DEBATE}

\section{Positive and negative implications of community-based education for various stakeholders}

\begin{tabular}{|c|c|}
\hline Positive implications & Negative implications \\
\hline \multicolumn{2}{|l|}{ Students } \\
\hline More one-to-one teaching & Travel \\
\hline $\begin{array}{l}\text { Opportunities to consult with } \\
\text { patients }\end{array}$ & $\begin{array}{l}\text { Accommodation } \\
\text { requirements }\end{array}$ \\
\hline $\begin{array}{l}\text { Enhanced opportunities for } \\
\text { feedback }\end{array}$ & Dispersal from "home base" \\
\hline \multicolumn{2}{|l|}{ GPs } \\
\hline Enhanced job satisfaction & Less time with patients \\
\hline $\begin{array}{l}\text { Adjunct academic } \\
\text { appointments }\end{array}$ & $\begin{array}{l}\text { Potential loss of } \\
\text { remuneration }\end{array}$ \\
\hline Prestige as educator & Educational training needs \\
\hline Increased complexity of work & $\begin{array}{l}\text { Increased complexity of } \\
\text { work }\end{array}$ \\
\hline \multicolumn{2}{|l|}{$\begin{array}{l}\text { Attracting new GPs into } \\
\text { workforce }\end{array}$} \\
\hline \multicolumn{2}{|l|}{ Involvement with assessment } \\
\hline \multicolumn{2}{|l|}{ Practices } \\
\hline Prestige as teaching practice & Extra rooms needed \\
\hline Extra staff for administration & Fewer appointments \\
\hline Enhanced IT infrastructure & Cost of IT infrastructure \\
\hline \multicolumn{2}{|l|}{ Patients } \\
\hline Involvement in education & Fewer appointments \\
\hline $\begin{array}{l}\text { Educating new generation of } \\
\text { doctors }\end{array}$ & Greater student presence \\
\hline Doctors more up-to-date & Giving consent \\
\hline \multicolumn{2}{|l|}{ Practice staff } \\
\hline Educational training & Fewer appointments to offer \\
\hline \multirow[t]{2}{*}{ Enhanced roles } & Student administration \\
\hline & Obtaining patient consent \\
\hline \multicolumn{2}{|c|}{ Universities/general practice departments } \\
\hline Expansion of training role & Quality assurance \\
\hline Research opportunities & Administration \\
\hline Provision of information to GPs & Flexible contracts with GPs \\
\hline Regular visits to practices & $\begin{array}{l}\text { Recruiting/retaining } \\
\text { practices }\end{array}$ \\
\hline \multicolumn{2}{|l|}{ Government } \\
\hline $\begin{array}{l}\text { Expanded general practice } \\
\text { workforce }\end{array}$ & $\begin{array}{l}\text { Change in general practice } \\
\text { payments }\end{array}$ \\
\hline $\begin{array}{l}\text { Health professionals as } \\
\text { educators }\end{array}$ & $\begin{array}{l}\text { Adequate resourcing/ } \\
\text { funding }\end{array}$ \\
\hline
\end{tabular}

- Review of the Practice Incentive Payment (currently \$100 per teaching session) to provide adequate levels of compensation to all GP teachers, as the current level does not cover loss in income and is only available to accredited general practices;

- Creation of a teaching infrastructure payment fund for general practices that equates to the current hospital-based schemes; and

- Specific funding to support the development of community clinical schools along the same lines as rural clinical schools to support each university's network of teaching practices.
We would also like to see:

- Development of a vertical curriculum for primary care training (as occurs with hospital-based training);

- Development of a Medicare item that reflects the emerging roles of GPs and general practice registrars as clinical educators (in a feefor-service structure); and

- Review of Practice Incentive Payments to acknowledge the GP preceptor's role as coordinator of each student's learning experience.

\section{Conclusion}

Clearly, a new set of principles and educational strategies is needed to ensure there are enough doctors with the right skills in the places where we need them. General practice-based education will meet the calls to

- reform clinical education so it meets the needs of tomorrow's clinical learners and the communities they serve; ${ }^{36}$

- create new models of apprenticeship to offer greater continuity to learners in clinical placements; and ${ }^{37}$

- prepare interns for practice in the 21 st century. ${ }^{38}$

The ideal clinical environment for all student and prevocational doctors will deliver the right mix of community and hospital-based learning.

\section{Competing interests}

None identified.

\section{Author details}

Jill E Thistlethwaite, MB BS, PhD, Associate Professor in Medical Education $^{1}$

Michael R Kidd, MD, FRACGP, Professor and Head ${ }^{2}$

Judith N Hudson, MB BS, PhD, Director ${ }^{3}$

1 Centre for Innovation in Professional Health Education and Research, University of Sydney, Sydney, NSW.

2 Department of General Practice, University of Sydney, Sydney, NSW. 3 Division of Clinical Education, University of Wollongong, Wollongong, NSW.

Correspondence: jthistle@med.usyd.edu.au

\section{References}

1 Australian Institute of Health and Welfare. Trend to shorter hospital stays continues. Media release, 25 Jun 1999. http://www.aihw.gov.au/mediacentre/1999/mr19990630.cfm (accessed May 2007).

2 Australian Institute of Health and Welfare. Use of general practice (GP) services. http://www.aihw.gov.au/cdarf/data_pages/gp_practice/index.cfm (accessed May 2007).

3 World Federation for Medical Education. The Edinburgh Declaration. Med Educ 1988; 22: 481-482.

4 General Medical Council, UK. Tomorrow's doctors: recommendations on undergraduate medical education. London: GMC, 1993.

5 Hensher M, Edwards N, Stokes R. International trends in the provision and utilisation of hospital care. BMJ 1999; 319: 845-848.

6 Murray E. Teaching internal medicine in general practice: an evaluation [PhD thesis]. Maastricht: Maastricht University, 2001.

7 Karmel P, chairman. Expansion of medical education. Report of the Committee on Medical Schools to the Australian Universities Commission. Canberra: AGPS, 1973.

8 Kidd MR. Is general practice vocational training at risk? Med J Aust 2003; 179: 16-17.

9 Lawson KA, Chew M, Van Der Weyden MB. The rise and rise of academic general practice in Australia. Med J Aust 1999; 171: 643-648.

10 Commonwealth Department of Human Services and Health. Rural doctors: reforming undergraduate medical education for rural practice. Final 


\section{GENERAL PRACTICE AND MEDICAL EDUCATION - FOR DEBATE}

report of the Rural Undergraduate Steering Committee. Canberra: AGPS, 1994.

11 World Health Organization. Community-based education of health personnel. Report of a WHO study group. Geneva: WHO, 1987. (Technical Report Series No. 746.)

12 Murray E, Jolly B, Modell M. Can students learn clinical method in general practice? A randomised crossover trial based on objectives structured clinical examinations. BMJ 1997; 315: 920-923.

13 Hastings A, Fraser R, McKinley R. Student perceptions of a new integrated course in clinical methods for medical undergraduates. Med Educ 2000; 34: 101-107.

14 Howe A. Patient-centred medicine through student-centred teaching: a student perspective on the key impacts of community-based learning in undergraduate medical education. Med Educ 2001; 35: 666-672.

15 Thistlethwaite JE, Jordan J. Patient-centred consultations: a comparison of student experience and understanding in two clinical environments. Med Educ 1999; 33: 678-685.

16 Thistlethwaite JE. Informed shared decision making and medical education [PhD thesis]. Maastricht: Maastricht University, 2004.

17 Oswald N, Jones S, Date J, Hinds D. Long-term community-based attachments: the Cambridge course. Med Educ 1995; 29: 72-76.

18 Halaas G. The Rural Physician Associate Program: successful outcomes in primary care and rural practice. Rural Remote Health [serial online] 2005; 5: No. 453. http://www.rrh.org.au/articles/subviewnew.asp?ArticlelD=359 (accessed May 2007).

19 Hansen LA, Talley RC. South Dakota's third-year program of integrated clerkships in ambulatory-care settings. Acad Med 1992; 67: 817-819.

20 Worley P, Silagy C, Prideaux D, et al. The parallel rural community curriculum: an integrated clinical curriculum based in rural general practice. Med Educ 2000; 34: 558-565.

21 Worley P, Esterman A, Prideaux D. Cohort study of examination performance of undergraduate medical students learning in community settings. BMJ 2004; 328: 207-209.

22 Worley P, Prideaux D, Strasser R, et al. Empirical evidence for symbiotic medical education: a comparative analysis of community and tertiarybased programmes. Med Educ 2006; 40: 109-116.

23 Margolis SA, Davies LM, Ypinazar V. Isolated rural general practice as the focus for teaching core clinical rotations to pre-registration medical students. BMC Med Educ 2005; 5: 22 (doi: 10.1186/1472-6920-5-22).
24 Martin AA, Laurence CO, Black LE, Mugford BV. General practice placement for pre-registration junior doctors: adding value to intern education and training. Med J Aust 2007; 186: 346-349.

25 Grant J, Southgate L. Pre-registration house officer placements in general practice. Milton Keynes, UK: Centre for Education in Medicine, Open University, 2000.

26 Joyce CM, Stoelwinder JU, McNeil JJ, Piterman L. Riding the wave: current and emerging trends in graduates from Australian university medical schools. Med J Aust 2007; 186: 309-312.

27 Howe A. Teaching in practice: a qualitative factor analysis of communitybased teaching. Med Educ 2000; 34: 762-768.

28 Thistlethwaite JE, Storr E. The views of general practitioner tutors on developing medical students' communication and management skills. Educ Primary Care 2004; 15: 370-377.

29 Health Workforce Queensland and Australian Rural and Remote Workforce Agencies Group. Doing the sums: will there be a future health workforce for rural and remote Australia? Brisbane: HWQ and ARRWAG, 2006.

30 Tolhurst $\mathrm{H}$, Stewart M. Becoming a GP - a qualitative study of the career interests of medical students. Aust Fam Physician 2005; 34: 204-206.

31 Australian Medical Workforce Advisory Committee. Doctors in vocational training: rural background and rural practice intentions. Aust $J$ Rural Health 2005; 13: 14-20.

32 Denz-Penhey H, Shannon S, Murdoch JC, Newbury JW. Do benefits accrue from longer rotations for students in rural clinical schools? Rural Remote Health [serial online] 2005; 5: No. 414.

33 Goodyear HM, Kennedy C, Wall D. Career choices: foundation year trainees' views on careers advice and information. Br J Hosp Med (Lond) 2007; 68: 211-214.

34 Woodcock I. Foundation Year 2: changing attitudes towards general practice. Br J Gen Pract 2006; 56: 895.

35 Larsen K, Perkins D. Training doctors in general practices: a review of the literature. Aust J Rural Health 2006; 14: 173-177.

36 Snadden D. Clinical education: context is everything. Med Educ 2006; 40: 97-98.

37 Irby DM. Educational continuity in clinical clerkships. N Engl J Med 2007; 356: 856-857.

38 Leeder SR. Preparing interns for practice in the 21st century. Med J Aust 2007; 186 (7 Suppl): S6-S8.

(Received 19 Apr 2007, accepted 17 May 2007) 